\title{
Subcutaneous emphysema resulting from surgical extraction without elevation of a mucoperiosteal skin flap
}

\author{
María Peñarrocha ${ }^{1}$, Javier Ata-Ali ${ }^{2}$, Celia Carrillo ${ }^{3}$, Miguel Peñarrocha ${ }^{4}$ \\ ${ }^{1} \mathrm{PhD}$, DDS. Associate Professor of Oral Surgery. Master of Oral Surgery and Implantology. Valencia University Medical and \\ Dental School. \\ ${ }^{2}$ DDS. Master in Oral Medicine and Surgery. Master in Oral Surgery and Implantology. Valencia University Medical and Dental \\ School. \\ ${ }^{3}$ DDS. Master of Oral Surgery and Implantology. Valencia University Medical and Dental School. \\ ${ }^{4} \mathrm{PhD}$, DDS. Professor of Oral Surgery. Director of the Master of Oral Surgery and Implantology. Valencia University Medical \\ and Dental School (Spain).
}

Correspondence:

Cirugía Bucal. Clínicas Odontológicas.

Gascó Oliag 1

46021-Valencia. Spain

E-mail:miguel.penarrocha@uv.es

\begin{abstract}
Subcutaneous emphysema, is a rare occurrence in dental practice. It is usually benign and self-limiting; nevertheless, severe consequences can result from surgical treatment. Emphysema occurs when air is injected into the subcutaneous layer of the tissue, this may come from either an air turbine handpiece or air syringe. Due to the danger of developing emphysema, procedures using compressed air are not recommended in dental extractions involving the raising of a skin flap, bone sectioning or exeresis. Two determining factors are always involved with subcutaneous emphysema. On the one hand, a compressed air procedure (air turbine handpiece, air-water syringe), and on the other, a communication between the oral cavity and deeper tissue producing dissection. Early diagnosis and treatment are critical to prevent the trapped air leaking into other areas.

The aim is to present a case of subcutaneous emphysema related to dental extraction, without raising a mucoperiosteal flap, possibly caused by close contact between the air turbine handpiece and the tooth during sectioning which forced air into the subcutaneous tissue.
\end{abstract}

Key words: Subcutaneous emphysema, high pressure air instruments, dental procedure. 


\section{Introduction}

Subcutaneous emphysema, is a rare occurrence in dental practice. It is usually benign and self-limiting (1); nevertheless, severe consequences can result from surgical treatment. Emphysema occurs when air is injected into the subcutaneous layer of the tissue, this may come from either an air turbine handpiece or air syringe (2). Due to the danger of developing emphysema, procedures using compressed air are not recommended in dental extractions involving the raising of a skin flap, bone sectioning or exeresis. Early diagnosis and treatment are critical to prevent the trapped air leaking into other areas.

The aim is to present a case of subcutaneous emphysema related to dental extraction, without raising a mucoperiosteal flap, possibly caused by close contact between the air turbine handpiece and the tooth during sectioning which forced air into the subcutaneous tissue.

\section{Clinical Case}

A 44-year-old man with no clinical history of interest. The patient reported pain on chewing on the lower left second molar. Clinical and X-ray examination revealed a nonrestorable cavity and chronic periapical periodontitis. Surgical extraction was carried out by sectioning the roots using an air turbine dental sectioning handpiece, without raising a mucoperiosteal flap.

During the sectioning procedure (Fig. 1) the patient reported a swelling of the face with mild upper neck pain on the same side. An immediate swelling was observed of the upper and lower cheek and lower left eyelid, accompanied by audible and palpable crepitus.

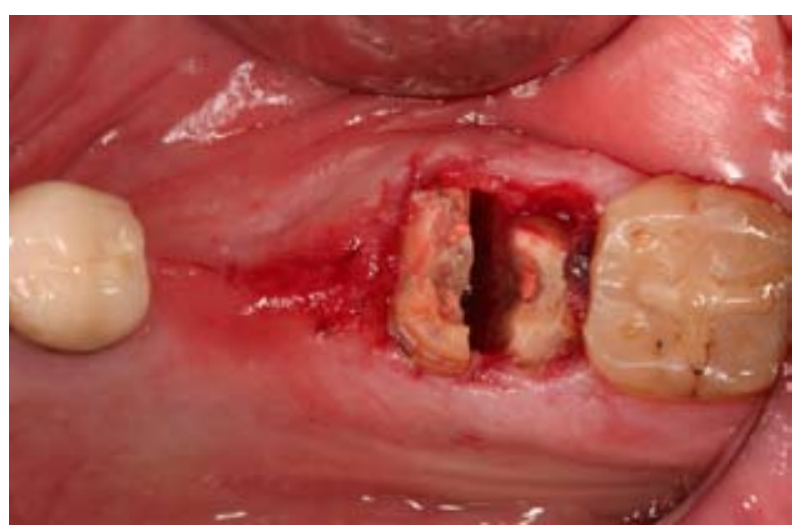

Fig. 1. Intraoperative image following surgical sectioning of the second lower left molar and appearance of the subcutaneous emphysema.

The extraction was completed and following curettage of the bone cavity a non hermetic suture was made. Treatment consisted of an anti-inflammatory (Ibuprofen $600 \mathrm{mg} / 8$ hours) and antibiotics (clavulanic Amoxicillin-ac. 875/125 mg/8hours / 7days).

After 48 hours the facial swelling had reduced slightly and the symptoms were less severe. Stitches were removed a week after surgery and on examination the patient was found to be asymptomatic.

\section{Discussion}

Several literature reviews of complications with respect to emphysema and dental procedures between 1960 and 2008 can be found. Heyman and Babayof (3) described 74 cases, $71 \%$ related with the use of an air syringe, high-speed handpiece or both; concluding that this is not a rare complication, being caused principally by dental extractions and restorative procedures. Arai et al. (2) included a review of 47 clinical cases of subcutaneous emphysemas and pneumomediastinum treated between 1994 and 2008, 18 of which appeared after a dental extraction. McKenzie and Rosenberg (4) reviewed 32 cases of subcutaneous emphysema produced during surgical procedures between 1993 and 2008. They observed that dental extraction was involved in 7 cases (6 for using an air-driven handpiece and the other of unspecified origin).

Heyman and Babayof (3) reported that subcutaneous emphysema affects the upper neck in $95 \%$ and the eye socket area in $45 \%$ of cases. Both areas were affected in the case presented in this study.

Two determining factors are always involved with subcutaneous emphysema. On the one hand, a compressed air procedure (air turbine handpiece, air-water syringe), and on the other, a communication between the oral cavity and deeper tissue producing dissection (Fig. 2). Some articles explain that air can penetrate through the radicular apex affecting principally the submandibular

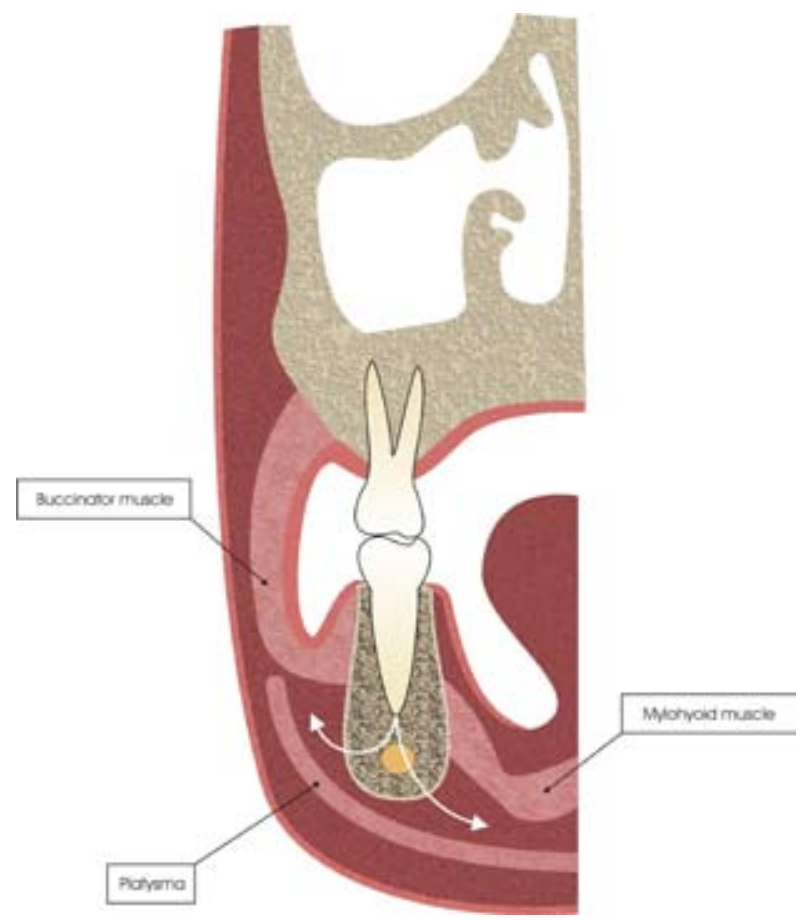

Fig. 2. Progression of the air dissecting the tissues in our patient. (A) Toward the lower cheek and palpebral region. (B) Toward the e266 cervical region. 
and sublingual area $(5,6)$. The facial muscle buccinators, connecting the maxilla and the mandible, act as a guide for the air which follows the line of least resistance. The roots of the first, second and third lower molars communicate directly with the sublingual and submandibular spaces. The sublingual space also provides a line of communication with the parapharyngeal, pterygomandibular and retropharyngeal spaces. This last area forms the principal connection from the mouth to the mediastinum (7). Air may penetrate the submandibular space which is delimited cranially by the mylohyoid muscle, laterocaudally by the superior fascia of the neck, and ventrocaudally by the anterior ventral portion of the digastric muscle.

Sekine et al. (8) recommend that any mucoperiosteal flap raised during a dental extraction should be kept as small as possible and not extend towards the lingual area of the molar alveoli. As indicated by Gamboa et al. (9), caution should be exercised with periodontal pockets over $4 \mathrm{~mm}$ or when there is little adhered gingiva due to the increased susceptibility of producing emphysema. It is recommended to maintain the greatest possible distance between the handpiece and the soft tissues and / or bone to prevent penetration of air, even in the absence of a mucoperiosteal flap.

Subcutaneous emphysema usually resorbs spontaneously without complications, and its treatment is symptomatic, as in the case of our patient (10). Clinical improvement is noted after 2-3 days, with minimal crepitus after 7-10 days. Antibiotic prophylaxis is accepted, since the air introduced through an intraoral location is likely to carry bacteria that can cause cellulitis or necrotizing fasciitis (4).

One point that may go unnoticed when sectioning teeth with an air turbine dental handpiece, without raising a mucoperiosteal flap, and that may trigger emphysema, is the close insertion of the handpiece into the tooth, we therefore recommend avoiding direct contact between the head of the handpiece and the tooth, as this may cause air to penetrate directly into the tissues. The point of interest in this study is to draw attention to avoiding close contact between the handpiece and the tooth. Perhaps due to its benign nature, this complication is more frequent than is reported in the literature. In this case a pathway was created by the surgical sectioning, and the close fit of the handpiece into the tooth forced air through the pathway into the subcutaneous tissue.

\section{References}

1. García Egido AA, García Herrera AL, Domínguez Fuentes B. Subcutaneous emphysema and pneumomediastinum after dental extraction. Med Clin (Barc). 2008;130:518.

2. Arai I, Aoki T, Yamazaki H, Ota Y, Kaneko A. Pneumomediastinum and subcutaneous emphysema after dental extraction detected incidentally by regular medical checkup: a case report. Oral Surg Oral Med Oral Pathol Oral Radiol Endod. 2009;107:e33-8.

3. Heyman SN, Babayof I. Emphysematous complications in dentistry,
1960-1993: an illustrative case and review of the literature. Quintessence Int. 1995;26:535-43.

4. McKenzie WS, Rosenberg M. Iatrogenic subcutaneous emphysema of dental and surgical origin: a literature review. J Oral Maxillofac Surg. 2009;67:1265-8.

5. Davies DE. Pneumomediastinum after dental surgery. Anaesth Intensive Care. 2001;29:638-41.

6. Barkdull TJ. Pneumothorax during dental care. J Am Board Fam Pract. 2003;16:165-9.

7. Yang SC, Chiu TH, Lin TJ, Chan HM. Subcutaneous emphysema and pneumomediastinum secondary to dental extraction: a case report and literature review. Kaohsiung J Med Sci. 2006;22:641-5.

8. Sekine J, Irie A, Dotsu H, Inokuchi T. Bilateral pneumothorax with extensive subcutaneous emphysema manifested during third molar surgery. A case report. Int J Oral Maxillofac Surg. 2000;29:355-7.

9. Gamboa Vidal CA, Vega Pizarro CA, Almeida Arriagada A. Subcutaneous emphysema secondary to dental treatment: case report. Med Oral Patol Oral Cir Bucal. 2007;12:E76-8.

10. Kung JC, Chuang FH, Hsu KJ, Shih YL, Chen CM, Huang IY. Extensive subcutaneous emphysema after extraction of a mandibular third molar: a case report. Kaohsiung J Med Sci. 2009;25:562-6. 